\title{
Uterine Contractions in Normal Labor Developed by a Positive Feed-back and Oscillation
}

\section{Kazuo Maeda*}

Department of Obstetrics and Gynecology (Emeritus), Tottori University Medical School, Yonago, Japan

\begin{abstract}
Aim: To clarify the developing mechanism of regular uterine contractions in the labor

Methods: The similarity of normal regular labor contractions of the uterus to the electrical oscillation was studied. The electrical oscillation technique was adapted to regular labor contraction of the uterus, where innervations between the uterus and brain were reported in animals in four papers.
\end{abstract}

Results: Interval between peaks of contractions was $2 \mathrm{~min}$ and the amniotic pressure was $40 \mathrm{mmHg}$ in typical labor contractions. Labor contractions were repeated from the onset of labor until the delivery of fetus. Attachment of reverse contraction curve to normal contraction curves formed sine wave-like repetition, similar closely to electrical oscillation waves. A positive feed-back was estimated from the uterus to the amplifying input

Comments: A biological amplifier is the hypothalamic center-hypophysis-oxitocin secretion, its output is uterine labor contraction, and its positive feed-back loop to the amplifier input is the innervations between the uterus and hypothalamus, of which presence was reported in animals. The biological positive feed-back loop produces oscillationlike regular uterine contractions, of which wave length is $2 \mathrm{~min}$, frequency $0.008 \mathrm{~Hz}$ and amplitude $40 \mathrm{mmHg}$.

Conclusion: Regular stable labor contractions of uterus is formed in the oscillation by the positive feed-back system composed of hypothalamus-hypophysis-oxitocin secretion, uterine contractions and uterus-brain innervations.

Keywords: Labor; Uterus; Contraction; Oscillation; Positive feedback; Innervation of uterus and brain; Electric simulation

\section{Introduction}

Regular uterine contractions in normal labor are expulsive power to deliver the fetus. The intrauterine pressure changes were recorded and studied in the measurement of labor contractions of uterus, while external tocodynamometry is common in clinical fetal monitoring [1]. The duration of contraction was about $1 \mathrm{~min}$ and interval was also 1 min, and the peak intrauterine pressure was 30 to $50 \mathrm{mmHg}$ in normal labor contractions, which was initiated at the pace-maker located at the corner of uterine fundus [1], it was conducted by the gap-junction [2] from the fundus to the cervix [1]. In addition, myometrial action potential was studied in details [3-5]. However, no mechanism of regular uterine contractions has been clarified, though the regular and constant myometrial contraction intensity would be important feature to push the fetus downwards and dilate the cervix. First step of studies was the detection of regular contraction, second the simulation of the repeated contraction comparing to electric oscillation in this report.

\section{Methods}

A typical uterine contraction was reported by Caldeyro-Barcia,

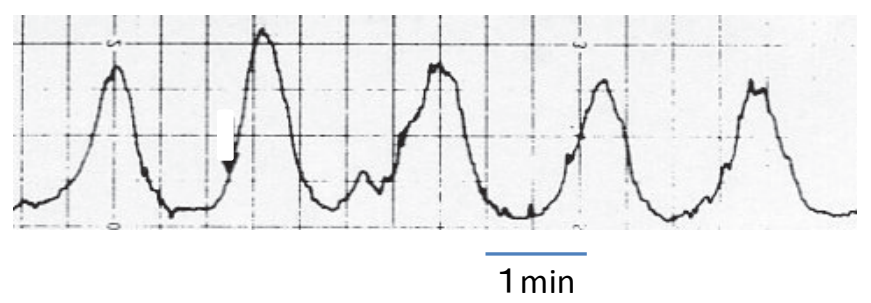

Figure 1: Regular uterine contractions recorded in the first stage of labor. The duration of uterine contraction is about one min and the interval also one min, i.e. the contraction cycle expressed by contraction peak-to-peak time is about two min. The contraction intensity is 30 to $40 \mathrm{mmHg}$ [3]. where repeated uterine contractions were found in amniotic pressure, of which intensity were approx. $40 \mathrm{mmHg}$, duration was approx. one min, and interval also1 min [1]. External tocodynamometry was objectively studied comparing to intrauterine pressure changes by us [3] (Figure 1).

The contraction curve was compared to the electronic oscillation in an experimental $2 \mathrm{MHz}$ ultrasound (Figure 2). The regularity of uterine contraction curve resembled the ultrasound waves; however, the difference was the presence of minus deflection of ultrasound waves, which was lost in uterine contraction. This is natural because uterine contraction is a biological uterine muscle action, but not the electrical information. Therefore, the uterine contraction curve was conversed upside down to make it minus deflection, and then attached to the base of original contraction curve. The combined curve showed a sine wave-like oscillatory change, where it was confirmed that the uterine contraction curve was the part of a biological oscillation (Figure 3 ). The result made it possible to analyze the labor contraction as an oscillation.

\section{Comments}

The developmental mechanism of electrical oscillation is a positive feed-back process in an electronic circuit composed of an amplifier and a positive feedback loop (Figure 4), where the electrical output is

*Corresponding author: Kazuo Maeda, Department of Obstetrics and Gynecology (Emeritus), Tottori University Medical School, Yonago, 3-125, Nadamachi, Yonago Tottoriken, 6830835, Japan, Tel: 81-859-22-6856; Fax: 81-859-22-6856; E-mail: maeda@mocha.ocn.ne.jp

Received June 28, 2013; Accepted September 03, 2013; Published September 08, 2013

Citation: Maeda K (2013) Uterine Contractions in Normal Labor Developed by a Positive Feed-back and Oscillation. J Health Med Informat 4: 130 doi:10.4172/2157 7420.1000130

Copyright: (c) 2013 Maeda K. This is an open-access article distributed under the terms of the Creative Commons Attribution License, which permits unrestricted use, distribution, and reproduction in any medium, provided the original author and source are credited. 


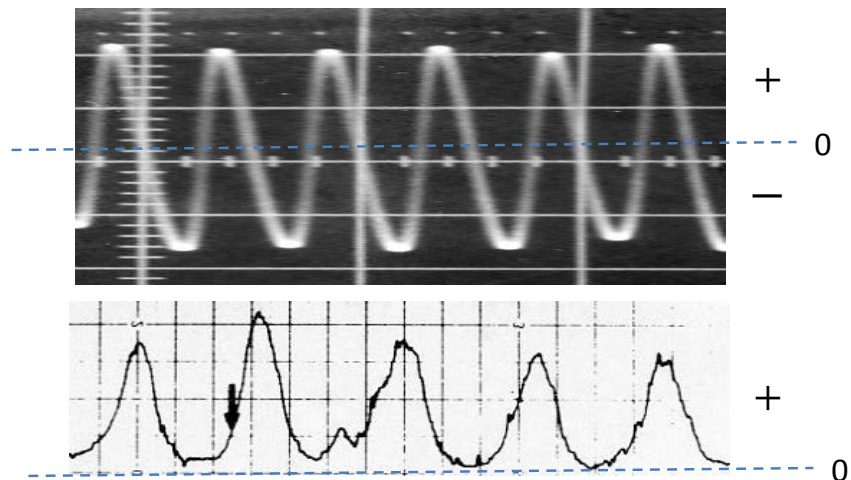

Figure 2: Upper curve is an oscilloscopic image of $2 \mathrm{MHz}$ continuous ultrasound wave, generated by a high-frequency generator. Lower one is uterine contraction curve illustrated in Figure 1. Both curves resemble each other, but uterine contraction curve has no minus deflection, that is natural because uterine contraction is a biological phenomenon.
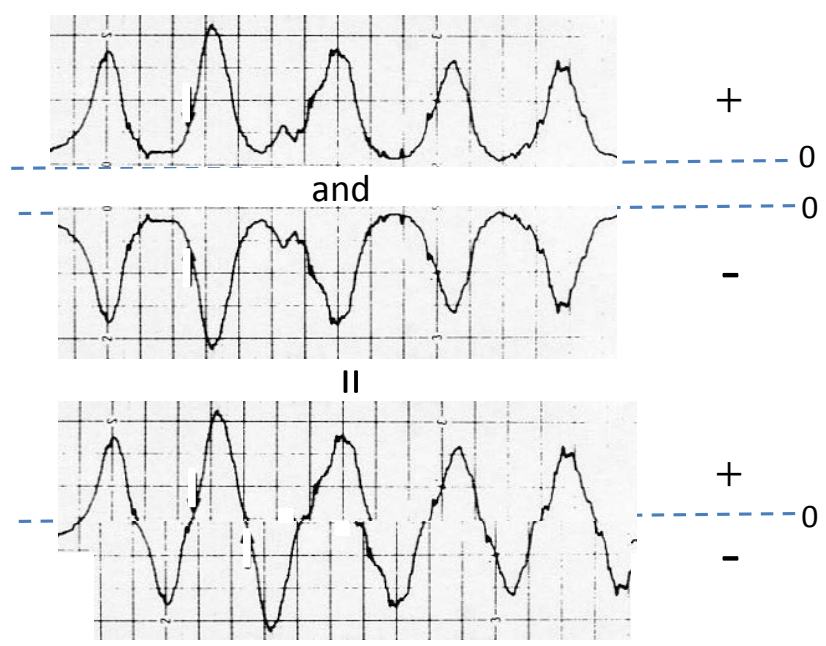

Figure 3: Positive uterine contraction curve (upper line) and reversed virtual negative deflection (middle line) is a sine wave-like oscillation (the lowest pattern), which was able to be analyzed as an oscillation.

partially fed back to the input of amplifier through a positive feed-back loop.

Since a labor contraction of uterus is a biological oscillation, a positive feed-back system is adopted to produce regular oscillation, where the amplifier is composed of the contraction promoting system, including hypothalamic nerve center, hypophysis and oxytocin secretion. The contraction amplifying system output is uterine contraction, and the contraction information is fed back to the input of the contraction promoting system through the innervations between the uterus and hypothalamus [6-9] (Figure 5). The frequency of oscillation developed by the biological positive feed-back system is approx. 0.008 $\mathrm{Hz}$ (the wave length is $2 \mathrm{~min}$, due to slow distribution of contraction in the uterus), and positive amplitude is approx. $40 \mathrm{mmHg}$. The labor contractions develop regularly with fixed frequency and amplitude in the oscillation, until the delivery of fetus.

The most important role of uterus-brain innervation will be to maintain the labor contraction to the most appropriate condition for the delivery of fetus, while the preeclampsia will be caused by

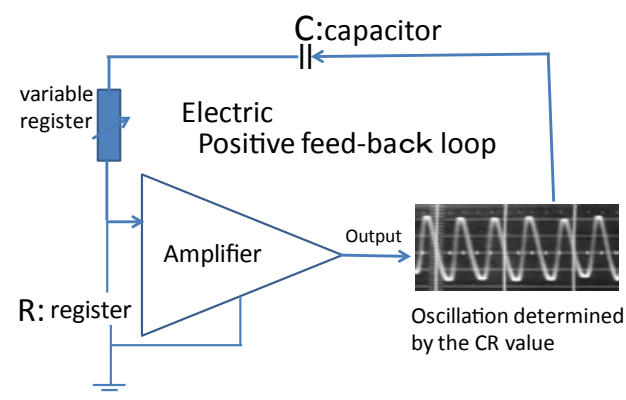

Figure 4: Electronic development of an oscillation by the positive feed-back system composed of an amplifier, positive feed-back of amplifier output to the input of the amplifier.

Nerves between the brain and uterus

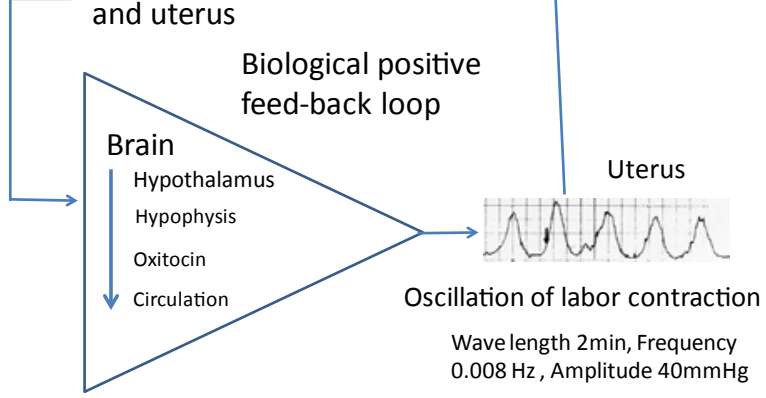

Figure 5: The biological development of oscillatory uterine contractions in normal labor with the biological positive feed-back system, including innervations between the uterus and brain.

the stimulation of hypothalamic sympathetic center continuously by enlarged uterus [10].

Abnormal labor contraction of uterus may be treated by the stimulation or suppression of a component of the positive feed-back system, e.g. in the repeated uterine contraction of a premature labor, the nerves between the uterus and brain will be deeply sedated to interrupt the positive feed-back loop by the paralysis of nerves. In contrast, a week labor pain will be treated by some stimulation of the uterus-brain nerves to develop normal positive feed-back. An anesthetic or analgesic medicine would be used to sedate the uterus-brain innervations in the treatment of a premature labor, while the innervations between the uterus and brain would be exited in the weak labor pain. New therapeutic strategies will be created after the studies on the positive feed-back system.

\section{Conclusion}

The development of regular labor contraction of uterus is provided by the oscillation of positive feed-back system in the loop composed of center of hypothalamus-hypophysis-oxitocin secretion, uterine contraction and the positive feed-back nerves of informing uterine contractions to the hypothalamus. New managements of abnormal labor contraction of uterus will be open after understanding the presence of positive feed-back and oscillation of uterine contraction in the labor with new pharmaceutical strategies.

\section{References}

1. Caldeyro-Barcia R (1960) Factors controlling the actions of the pregnant human uterus. In: 5 th conference on physiology of prematurity, Kowlessar M (Ed.), Princeton, Josia Macy Foundation, New York, USA 111-117. 
Citation: Maeda K (2013) Uterine Contractions in Normal Labor Developed by a Positive Feed-back and Oscillation. J Health Med Informat 4: 130. doi:10.4172/2157-7420.1000130

Page 3 of 3

2. Ikeda M, Kawarabayashi T, Sugimori H (1989) Changes in gap junctions in smooth muscle and endometrium of the pegnant rats. Nihon Heikatsukin Gakkai Zasshi 25: 250-252.

3. Tominaga Y, Ito T, Terahara M, Takahasi S, Maeda K (1973) Objective studies on external tocodynamometry. Chuugoku-Shikoku Obstet Gynecol 24: 25-28.

4. Leman H, Marque C, Condry J (1999) Use of the electrohysterogram signa for characterization of contractions during pregnancy. IEEE Trans Biomed Eng 46: 1222-1229.

5. Euliano TY, Skowronski M, Marossero D, Shuster J, Edwards R (2006) Prediction of intrauterine pressure waveform from transabdominal electrohysterography. $J$ Matern Fetal Neonatal Med 19: 811-816

6. Wiesel O, Toth IE, Boldokoi Z, Homyak A, Bokor V, et al. (2004) Comparison of transsynaptic viral labeling of central nervous system structures from the uterine horn in virgin, pregnant, and lactating rats. Microsc Res Tech 63: 244 252

7. Yellon SM, Grushan LA, Rambau GM, Leshuga TJ, Kriby MA (2010) Pregnancyrelated changes in connections from the cervix to forebrain and hypothalamus in mice. Reproduction 140: 155-164

8. Gnanamanickam GJ, Liewellyn-Smith IJ (2011) Innervation of the rat uterus at esterus: A study in full-thickness, immunoperoxidase-stained whole-mount preparations. J Comp Neurol 519: 621-643.

9. Poletini MO, McKee DT, Szawka RE, Bertram R, Helena CV, et al. (2012) Cervical stimulation activates $\mathrm{A} 1$ and locus coeruleus neurons that project to the paraventricular nucleus of hypothalamus. Brain Res Bull 88: 566-573.

10. Maeda K (2013) Preeclampsia is caused by continuous sympathetic excitation due to an enlarged pregnant uterus. J Perinat Med 12: 1-5 